\title{
City intelligence for enhancing urban performance value: a conceptual study on data decomposition in smart cities
}

\author{
Karima Kourtit ${ }^{1,2,3,4,5}$ (D)
}

Received: 19 May 2020 / Accepted: 23 January 2021 / Published online: 19 February 2021

(C) The Author(s) 2021

\begin{abstract}
The contemporary 'digital age' prompts the need for a re-assessment of urban planning principles and practices. Against the background of current data-rich urban planning, this study seeks to address the question whether an appropriate methodological underpinning can be provided for smart city governance based on a datadriven planning perspective. It posits that the current digital technology age has a drastic impact on city strategies and calls for a multi-faceted perspective on future urban development, termed here the 'XXQ-principle' (which seeks to attain the highest possible level of quality for urban life). Heterogeneity in urban objectives and data embodied in the XXQ-principle can be systematically addressed by a process of data decomposition (based on a 'cascade principle'), so that first, higherlevel urban policy domains are equipped with the necessary ('big') data provisions, followed by lower-ranking urban governance levels. The conceptual decomposition principle can then be translated into a comprehensive hierarchical model architecture for urban intelligence based on the 'flying disc' model, including key performance indicators (KPIs). This new model maps out the socio-economic arena of a complex urban system according to the above cascade system. The design of this urban system architecture and the complex mutual connections between its subsystems is based on the 'blowing-up' principle that originates from a methodological deconstruction-reconstruction paradigm in the social sciences. The paper advocates the systematic application of this principle to enhance the performance of smart cities, called the XXQ performance value. This study is not empirical, although it is inspired by a wealth of previous empirical research. It aims to advance conceptual and methodological thinking on principles of smart urban planning.
\end{abstract}

Keywords Smart cities · Information - Stakeholders · Big data · Capacity · Capability $\cdot$ Intelligence $\cdot$ Cascade $\cdot$ Decomposition $\cdot$ Flying disc $\cdot$ Blowing-up principle

Karima Kourtit

k_kourtit@hotmail.com

Extended author information available on the last page of the article 


\section{Introduction: 'Urbi et Orbi'}

Human settlement systems are not the result of random forces, but reflect regularity and order that is partly imposed by the physical geography of our world, but is also partly the result of complex economic, social and political forces. For example, the geographical division of the space-economy into urban and rural areas is not purely a natural phenomenon, but is functionally co-determined by demographic developments, technological progress, smart specialisation, and economic scale advantages. This division into 'urbi et orbi' is not a strict and fixed geographical division that is crafted in stone, but shows a time-varying development pattern determined by human choices. This is clearly reflected in the changes in degrees of urbanisation in various countries over the past centuries, which show a great diversity in outcomes in different countries or continents and in different time periods (Nijkamp et al. 2020).

Nowadays we live, according to United Nations (UN), in the 'urban century'. This means that our world is becoming increasingly urbanised, with more people living in urban areas (including suburbs and metropolitan areas) than in rural areas. Not only are the shares of urban vs. rural inhabitants changing, but also the socio-geographic composition within these two groups of people. For example, several villages in rural areas are at present reinforcing their economic position by attracting highly educated residents, while many large cities and urban areas are moving up into the class of mega-cities with mass labour pools. This profound dynamism between urbanity and rurality is called by Kourtit (2019) the 'New Urban World'.

This 'New Urban World' manifests itself as an unprecedented reinforcement of large urban agglomerations. These 'big cities' are becoming the new powerhouses in our world and, in a recent publication, have even been called 'urban empires' (see Glaeser et al. 2020). But the pressing question is: What makes these urban agglomerations powerful? What are the critical success factors for the enhancement of these cities' socio-economic performance or for their creation of world-class value by these cities? What are the consequences of drastic changes in the 'urbi et orbi' patterns in our world? And how should urban governance be organized so as to ensure an urban planet that meets the well-known UN SDGs (Sustainable Development Goals)?

There is no doubt that big cities and urban agglomerations act as powerful magnets for human activity, as a result of possessing a great variety of urbanisation advantages. But not all urban areas share the benefits of city formation and expansion to the same extent. Several cities (e.g., New Delhi, Beijing, Djakarta, Lagos, Sao Paulo) are even suffering from severe negative scale externalities caused by pollution, congestion, or crime.

In addition to the global urbanisation trend, there is another powerful megatrend, viz. the rise of information and communication technology (or digital technology). This revolutionary change in information handling technology has already had far-reaching implications for urban planning (see e.g. Kourtit 2020), and will drastically change the practice of smart urban planning in the future. 
The present study seeks aims to develop and present the cornerstones and contours of an appropriate methodological and conceptual framework for smart city governance in a data-rich urban environment. It also seeks to identify the critical success factors that are necessary to build intelligent urban management and strategic policy directions for large cities, so that they can play a significant role at the national or even worldwide platform of urban competitiveness, against the background of unprecedented advances in digital technology.

In our contribution, we argue that-even though a digital orientation or revolution in cities and their institutional fabric may be a necessary condition-the digital fix is by no means a sufficient condition. For a city to achieve the ambitious targets of positioning itself as a creator and accelerator of world-class added value (in terms of, e.g., SDG performance), it is necessary to have a different mindset, which meets at least two conditions: (1) an organised structure of data systems and data-handling capacities, following a decomposition or cascade architecture; (2) a hierarchical governance system of city intelligence that is able to reap the fruits of the current digital age for the urban economy. The overriding goal of cities in the digital urban century would need to be the achievement of the highest possible quality of urban life in cities (an idea called the XXQ-principle by Nijkamp 2008). ${ }^{1}$ Consequently, obtaining the label of a 'smart city' is only a privilege for a limited number of dedicated cities; a smart city is not based on an unspecified goal or a governance dream, but on a testable achievement as compared with other cities. Thus, to become (and to remain) a high-performing and world-class smart city, a strategic and operational framework for urban governance is needed that is based on goal-oriented transparency, reliable and systemic information management, flexible and resilient policy behaviour in uncertain times, and a critical monitoring of the paths forward.

It is thus clear that in the digital era urban planning is 'work in progress'. While old problems have not yet been sufficiently solved, problems (e.g., pandemics, disasters, lack of security) are coming up. Thus, the question emerges: how to develop a new data-driven architecture and methodology that will support sustainable and inclusive urban development goals?

This study is not an empirical research paper, although it is inspired by a wealth of previous empirical research; it aims to advance conceptual and methodological thinking on principles of smart urban planning. The paper provides a conceptual architecture for smart urban policy and is organised as follows. In Sect. 2, we will sketch out briefly digital promises for smart city policy. Section 3 will present some elements of world-class value creation based on the so-called XXQ-principle, followed by a brief review of selected relevant literature in Sect. 4. Next, Sect. 5-the core of our study - maps out in more detail the conceptual architecture of worldclass performance management by smart cities, in which the methodological core

\footnotetext{
1 The XXQ-principle refers to the collective urban goal to realise the highest quality of urban life (Q stands for quality, and XX for the highest value). This goal is not achieved by a single measuring rod, but represents a multidimensional set of urban performance indicators, whose integrated and aggregated values signify the degree to which the complex XXQ value is achieved. The underlying assumption is that a city is a complex multi-actor system that is driven by the generic objective of creating or enhancing a maximum quality of urban life (XXQ).
} 
concept of what is here called the 'flying disc' will be introduced and developed into the new 'blowing-up model'. This will then lead to a discussion of smart city principles, followed by a retrospective and prospective conclusion.

\section{Digital promises}

In the past decades, a new term has entered the urban science, viz. 'smart cities'. A fundamental and systematic description of the multiple dimensions of this concept was provided by Giffinger and Haindl (2009), who distinguished six prominent dimensions of smart cities. The current rise of 'smart cities' is a clear manifestation of the relevance of advanced urban data management and intelligent city governance that is stimulated by the current digital age. Smart cities use the fruits and opportunities of the digital era to reinforce their economic, social, technological or political position in a nation-wide, continental or worldwide arena (see an original study by Komninos and Kakderi 2019). 'Big data' analytics, machine learning and artificial intelligence, data mining, and IoT applications have become the new buzzwords for urban management and policy. But will all this ensure a winning position for cities from a global or national perspective? Clearly, the ultimate question is whether smart cities have a higher performance. In other words, do smart cities and smart urban policies contribute to a higher efficiency in the provision of public services and in the advancement of private activities? A recent study (Tureckova and Nevima 2020) advocates a cost-benefit approach to answer this cumbersome question.

It goes without saying that cities need to have professional and up-to-date data systems in a multi-actor setting to make good and transparent decisions and to develop smart and shared actionable strategies. The increasing complexity, diversity and volatility in managing modern smart city systems all seem to lead sometimes to 'fata morgana' images of future cities, without considering the real and hard facts. This is often aggravated by the permanent flux of unstructured, multiple-source and multidimensional data ('big data') systems (often uncontrolled), the permanent pressure to improve the current weak data transformation and data analytics approaches, and the frequent unfortunate misinterpretations, as well as poor strategic alignments with planned policies and strategies that are subject to changing external conditions, fuzzy goals, and speculative policy actions. The complex arena of multiple dimensions, diverse stakeholders, and different geographical and network scales add yet another complication for a solid sustainable strategy for cities.

Nowadays, the trend breach caused by digital technology, the pervasive use of modern information systems, and the rise of intelligence tools and data analytics provide a unique cognitive opportunity and actionable capability for many urban policymakers, actors and stakeholders to use and analyse large volumes of multidimensional data (often 'big data'). A wealth of professionally structured data may provide cities with a reliable evidence-based basis for developing and offering a structurally improved quality of life, better overall health and safety conditions, and an unprecedented intensity of knowledge, on the basis of smart and intelligent solution strategies. This new data era forms a powerful strategic and smart datahandling driver, moving from fuzzy and disconnected dimensions towards reliable 
information systems and data-driven strategies. In this way, an urban system may become more accountable, efficient, and actionable with a view to gaining a strong and clear competitive edge in a supra-regional or even global urban system.

Digital technology provides various stakeholders in the city system with internal and external up-to-date information for designing and using intelligent evaluation frameworks for location-based smart decision-making and spatial strategies (see Kitchin 2015). It helps city leaders to manage new types of applied data analytics-from 'policy analysis to policy analytics' (Kourtit and Nijkamp 2018)—which can further enhance actionable, evidence-based and accountable policymaking by developing and evaluating cognitive-based alternative policy options, conditions and criteria so as to manage the issues of a championing smart city.

In the light of the great opportunities of digital technology, the present study draws up the principles and cornerstones for smart data analytics and city intelligence capability (interpreted here in the sense of Sen 1999). Here, we design the architecture of a professional data-based urban future development strategy, on the basis of a decompositional framework in the form of an information cascade for smart city policy, in particular from the viewpoint of creating world-class or at least high-quality value. Data-driven smart urban policy does not aim to acquire a maximum volume of data, but to filter massive data so as to obtain a useful, systematic and fit-for-purpose database. This is what we call in our study digital 'city intelligence'.

Our study is mainly methodological and conceptual in nature. It is however, inspired by a wealth of literature (see the Reference list), but has its roots in research practice in various cities (see e.g. Kourtit and Nijkamp 2018).

\section{Championing smart cities: setting the scene}

The wide array of emerging powerful digital and related network-opportunities and their positive externalities for smart city systems - as a result of the overwhelming supply of modern and interconnected ICT artefacts and permanent inventions - is changing the governance landscape and managerial practice concerning how cities can orchestrate their efforts in creating added value and enhancing their performance in an open globalising system. Nowadays, to generate a highly synergetic and sustained added value to obtain a world-class performance position that maximises urban XXQ, smart cities have to address several challenges in building up a transparent space-time information framework so as to obtain and ensure the high quality of knowledge-based information that is necessary for managing and enhancing urban wellbeing and competitiveness. This goal-achievement strategy seeks to design a new image of the city, viz. a 'sustainable smart home' (see Kourtit 2019) for an urban community, together with multiple stakeholders and urban science experts. Modern citizen science (see, e.g., Riesch and Potter 2014; Ceccaroni and Piera 2017; McKinley et al. 2017) tells us that the strategic partnerships of interested parties and the commitments of socially-aware citizens are the cornerstones to develop a reliable and balanced 
action framework supported by decision support tools in the form of socio-economic 'health checks' - for instance, by means of actionable dashboards-of the city system concerned.

Today, most large cities operate nowadays in an open and often competitive global system seeking to maximise their XXQ. In this context, to achieve the (competitive) performance such a championing city requires a complete picture of the city's strategic future achievements and value creation from a balanced multidimensional view (Ho and McKay 2002; Kourtit 2019; Kourtit and Nijkamp 2018). Clearly, the search process for a successful or new road towards a highperforming championing city, and for a concerted strategy for smart and intelligent decisions-ranging from day-to-day to long-range strategic decisions, while continuously anticipating changing circumstances-has drastically changed in recent years (Kitchin and Perng 2016).

It is noteworthy that evidence-based policies are nowadays increasingly data-driven. Ongoing efficient data collection, the subsequent intelligent data transformation, and smart urban governance and evaluation on the basis of evidence-based city 'health checks' are necessary from both an economic and noneconomic perspective (e.g., mobility, health, safety and security, public amenities, public transport, quality of life, tourism, climate change). Smart city governance thus presupposes information on past and anticipated future achievements; necessary policy handles and measures; and unforeseen external trends and drivers, in using modern (digital) technologies. Clearly, this process needs to be supported by sophisticated digital and information methods and intelligent decision tools to monitor urban achievements, and to design and suggest new and unknown strategic policy directions and related (sometimes preventive) actions, as well as to identify both important gaps and real threats and opportunities (as stimuli for added value) that may take place in a competitive urban environment (see Batty 2013).

As already mentioned, the present paper aims to shed new light on the significance of modern data and information systems for smart spatial planning, especially in the spirit of a smart city context. In particular, the study aims to introduce multidimensional data ('big data') tools for assessing aligned values and conditions in the relationship between managing smart urban (or spatial) strategies and solutions and maximising the achievement of a sustainable and healthy city. Such a city should have a focus on well-being and quality of living and working in a broad sense (see also the above-mentioned XXQ concept, referring to the achievement of the highest quality of urban life, as introduced by Nijkamp 2008). A consistent XXQ-orientation may be seen as the key for becoming and staying a high-performing successful smart city (Nijkamp and Kourtit 2013). The challenging question in modern city governance is not how many different types of data to collect and to use in urban management and policy, but how to organise the rich information base for enhancing XXQ, so that the smart city becomes a championing (i.e., intelligent) city (see Kourtit et al. 2020b). This ambitious task calls for a systemic data-driven view on city governance. This challenge will be addressed in Sect. 5, after a concise literature discussion in the next section. 


\section{Literature review}

The literature on urban development and planning is vast and too wide-ranging to be summarised here (see for an overview e.g. Baycan et al. 2008). In the present section, we will only zoom in on a selection of studies devoted to smart city policy. Our study on smart city's value added is embedded in several research orientations, ranging from urban and regional planning to urban design theory. Thus, multiple disciplines provide the conceptual cornerstones of the present study. Such basic ingredients have to be incorporated into urban economic development and smart city strategy, so as to support the evaluation of the complex urban multi-level quality of life (the XXQ-principle), which is essentially based on place-making theory on cities. It should be noted that in particular, quantitative data-driven and evidence-based studies are useful for a solid assessment of urban performance, including in particular citizens' perceptions and values regarding the public space in a smart city.

The literature on smart cities has a broad coverage ranging from methodological principles to case studies (see also Caragliu et al. 2011). Our study adopts a meso-/macro-oriented development perspective on cities, and is inspired by several recent spatial and urban dynamics studies (see, e.g., Capello and Nijkamp 2009; Stimson et al. 2011). In particular, we refer in this context to the importance of spatial innovation theory-which is associated with spatial endogenous growth theory (see e.g., Kourtit et al. 2015a, b, 2017, 2019; Stough et al. 2018) and modern agglomeration theory-usually associated with the New Economic Geography (Brakman et al. 2011; Kourtit et al. 2011; Fujita and Thisse 2002, 2012; Acs and Armington 2006; Crescenzi and Rodriguez-Pose 2008; Karlsson et al. 2011; Redding 2010). These studies have been source of inspiration for a broad range of complementary empirical studies (see, e.g., Kourtit and Nijkamp 2013a; Kourtit et al. 2020a) which proposed the application of these conceptual and theoretical frameworks for monitoring and assessing the performance of urban space in smart cities (Stough et al. 2018). The overall objective of a smart city's system would then be to optimise its XXQ, seen from the angle of both its local and its global potential, as well as from its capability to ensure citizen-oriented, socio-economic and sustainable development in a balanced and sustainable way (see Kourtit et al. 2014, 2015a).

In the remaining part of this section on smart cities, we will focus in particular on: definitional issues, the new data orientation of smart cities, the use of data for smart urban design, and the assessment of urban performance from the perspective of the XXQ-principle.

The notion of smart cities is nowadays gradually becoming a new paradigm for enhancing sustainable urban development through intelligent decision tools to gain a competitive advantage in terms of their XXQ value, which entails the strategic redirection of aligned choice options for urban developments. The rational expectation is that the smartness of a 'power city' or a 'world-class city' will reinforce the strategic position of that city in an arena of fierce competition and unanticipated-and sometimes unexpected-transformations (Caragliu et al. 
2011; Chourabi et al. 2012; Neirotti et al. 2014; Cocchia 2014; Albino et al. 2015). There is a wealth of literature on the definition of a smart city; in most cases, the smart city concept - and its many variants and extensions-emphasises the importance of institutional and social elements in the city in relation to the potential of digital technologies in serving as an advanced tool for intelligent sustainable city management (Coe et al. 2001; Berry and Glaeser 2005; Hollands 2008; Shapiro 2008; Caragliu et al. 2011).

Defining, measuring and managing the performance capacity of sustainable smart cities have received major attention in recent years in the literature (see also Giffinger and Haindl 2009; Hollands 2008; Cohen 2014; Kourtit and Nijkamp 2018; Komninos and Kakderi 2019). In the same spirit, various studies have focused on assessing the intrinsic spatial dimension and land use in smart cities (Komninos 2011; Lombardi et al. 2012; Kourtit and Nijkamp 2013b; Angelidou 2014), for instance, through the use of geoscience and visualisation techniques. It is noteworthy that-given the broad spectrum of interest in modern smart cities-there is in fact not one single analytical and operational conceptualisation and operationalisation of smart cities; the various smart city notions used in the literature represent a complex array of different meanings and sets of (sometimes uncoordinated) critical performance predictors [in particular, key performance indicators (KPIs)] and assessment systems (e.g., SWOT analysis, multi-criteria analysis) in evaluating and predicting the level of managerial maturity and the smartness content of a city's performance strategy from a multidimensional, partly non-economic, valuation perspective (e.g., Cohen 2014; Martens and Weijers 2000).

In the age of digital technology development, one of the most recent, and rapidly growing research challenges is the potential to monitor and measure the 'health system' of a city, comprising, inter alia, indicators for urban quality of living and working, opportunities, safety and security, access to public amenities, as well as the residents' perception of happiness. Here, digital orientation plays an important role, and therefore, the use of urban computing (Zheng et al. 2014) or urban informatics (Foth 2008) has drastically increased, inter alia, by introducing and supporting spatial data-based tools for assessing and measuring the perception of the city and the constituents of quality of space and urban systems. This novel approach is also a source of inspiration for client-oriented and individualised modern assessment methods and models in the context of a multi-dimensional performance analysis, as will be shown hereafter.

The operational bases for a solid data-driven quantitative assessment of key features, as defined by prominent urban theorists and urbanists (e.g. Gottdiener 1985; Castells 1996; Lefebvre 1947, 1969, 1991, 1996, 2003; Saunders 1981; Brenner 2013; Harvey 2014) and used by prominent 'place-makers' (e.g. Jacobs 1961, 1969, 1998; Whyte 1956, 1989; Gehl and Gemzøe 2001), were recently put forward by Ewing and Clemente (2013), amongst others, to assess the significance of critical performance indicators for determining, in a relative sense, the success of the intelligent management of a city and of urban space. Meanwhile, a similar approach was advocated for estimating the citizens' perception of quality of life in a quantitative way (cf. the above XXQ concept), to map out the broader capability and action arena of a city that will cause it to qualify as a world-class city (e.g. Nadi et al. 2016). 
Many urbanists (e.g., Park et al. 1925; Zorbaugh 1929; Wirth 1938) have been searching for answers to what characterises a high quality of urban space, which at the same time ensures a liveable space and an interactive system (social urban capital) that brings people together. In particular, Lynch (1960), Jacobs (1961), Cullen (1961), Alexander (1964), Alexander et al. (1977), and Gehl (1987) have tried to define which key elements of the urban structure determine the performance of city spaces or shape the residents' urban perceptions.

Starting from traditional theories, Ratti et al. $(2010,2016)$ have recently delved deeper into the subject of the 'sense of place', human cognitive processes and, even more important, the perception of the built environment in the city (Silberberg et al. 2013). These new research challenges and concerns have provided the basis for understanding the important role of place-making, also reflected in 'people-centred planning' (Friedmann 2010; Tuck et al. 2014; Tuck and McKenzie 2015; Courage and McKeown 2019). This notion may, in principle, be extended to a new urban design characterised by a 'sense of place' framing that is created by historical and site-specific interests and impressions (see, e.g., Corner 1999; Bianca 2001; Allison and Peters 2011; Kasprisin 2011; Bartolini 2013; Erkan and Ceccarelli 2017; Kropf 2017; Mosler 2019).

In the age of the development of sophisticated digital tools, the potential for measuring health, well-being and quality of urban design and the perception of urban 'love' (see Kourtit et al. 2020a) is growing. Interesting contributions on the quantitative assessment of the elements of the critical urban performance factors can be found in the informative book of Ewing and Clemente (2013). The authors reviewed the urban design literature and identified eight essential quantitative metrics (viz. imageability, complexity, coherence, enclosure, human scale, legibility, linkage, and transparency) that may have a significant effect on the health and quality of city space and the urban perception of attractiveness in a modern network society. The conceptualisation of the urban design qualities used in their research framework can be further used as a useful input for an operational representation of a framework for how to manage a championing city's high performance, which is: (1) geared towards the highest possible long-term added value; (2) characterised through various dimensions of important linkages with different core functions; and (3) put together in a new general conceptual framework.

This section has summarized a wealth of literature on urban planning challenges in the new digital era. Knowledge on a rich variety of reflective and empirical studies has inspired us to design operational principles for intelligent urban governance, which may be seen as signposts for modern data-driven city governance. This will be further articulated in the next section.

\section{Architecture of world-class performance management of cities}

As argued in a recent study (Glaeser et al. 2020), in the age of urbanisation, cities tend to act as 'empires', with a strong sense of competitiveness in many respects (growth, quality of life, tourism, culture, education, recognition etc.). To provide systematic policy-support information for the great variety of urban 


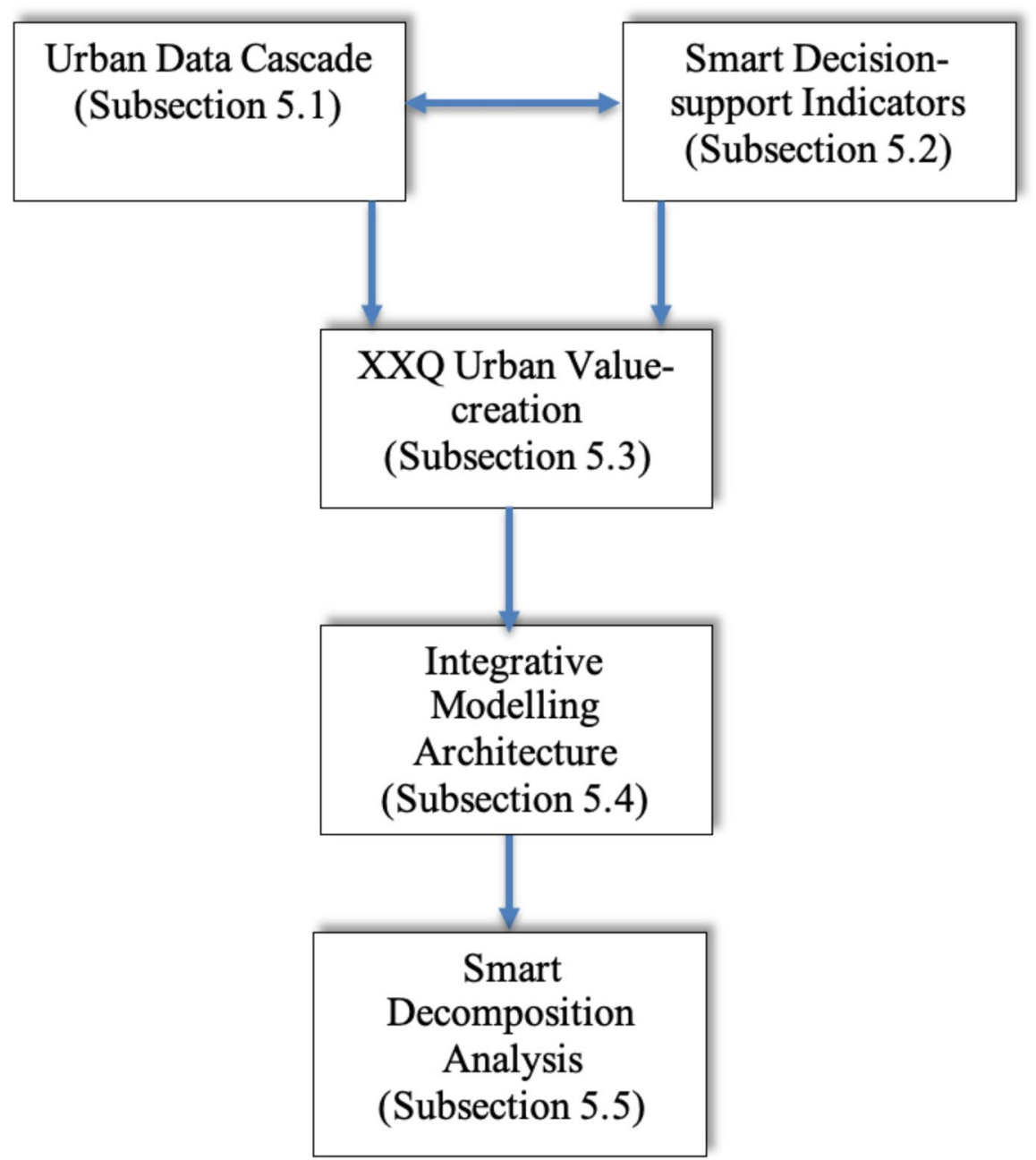

Fig. 1 Integrated building blocks for an intelligent policy constellation of a complex city fabric

development goals, an integrative architecture is needed where policy strategies and tailor-made information come together. Smart city policy seeking to enhance the performance of cities and aiming at urban value creation calls for a structured underpinning. In the present section, we will design and present a systematic methodology for achieving a high(er) urban performance value (see Fig. 1). The elements of this architecture (an 'intelligent city fabric') will be next elaborated in Sects. 5.1, 5.2, 5.3, 5.4 and 5.5. 


\subsection{An urban information decomposition and cascade approach}

In the current era, smart cities in our world meet at the cross section of the 'urban century' and the 'digital data century'. At this cross section of mega-trends, two important questions arise: (1) does the trend towards more and bigger cities also lead to an upscaling in the quality of urban settlements (ranging from towns to mega-cities)?; (2) does the deluge of masses of data also lead to better urban decisions and policies (both private and public)? Thus, smart cities face the challenge to enhance their XXQ by the intelligent use of the unprecedented avalanche of ('big') data (see Kourtit et al. 2020b).

An unstructured use of tonnes of data [ranging from official urban statistical data (e.g., from population registers) to informal social media data (e.g., on visitor's perceptions of the quality of a local museum)] does not add to a systematic insight into the necessary information for complex policy issues in a city (e.g., the housing needs of migrant workers, human health conditions in densely populated districts in the city, the happiness of elderly citizens, etc.). Therefore, the proper systemic organisation of data for public and private use in a city is a sine qua non.

In the present section, we address the complex urban data fabric in a modern digital-driven city by advocating a novel architecture of available or required data, based on the cascade principle. Just as running water in a mountainous area follows certain predictable routes (determined by physical areal conditions and the law of gravity law), the complex collection and use of many heterogeneous data needs to follow the route towards concerted decision and policy needs, where, in the first place, high-priority urban policy domains are served with tailor-made data, while lower-order priority needs will be served in the later stage of the urban data cascade. This data decomposition is visualised in Fig. 2.

Figure 2 illustrates that higher-order (often aggregate strategic) data are first employed at the higher — often strategic - policy level of a city (e.g., urban expansion, traffic management), while more detailed (e.g., street, group or individual) data are used in the lower levels of policy interest (e.g., improvement of the construction of a high school, repair of a street pavement).

The previous cascade model has an elegant logic, but one important issue needs to be addressed, viz. the priority ranking of different fields of urban interest. Here, we resort to the decomposition principle advocated by Simon $(1955,1962)$ who has addressed a systemic view of complex decision-making. Any dynamic and interdependent system can be decomposed into individual subsystems which incorporate some degree of autonomic governance or functional independence. Examples of such systems in a city are: local taxation systems, demographic growth, labour and housing market systems, availability of open public space (e.g., parks), medical health care systems, and so forth. These urban subsystems can then be decomposed into smaller sub-subsystems on the basis of the cascade principle. The decomposition principle ensures an integrated and functionally determined view, with real-time situational (internal and external) interfaces, in the hierarchy of urban structures.

In the remainder of this section, we will use the cascade and decomposition principles as building blocks for the cognitive-oriented operation of an intelligent city. We provide a stepwise presentation of the overall data architecture of a smart city by 


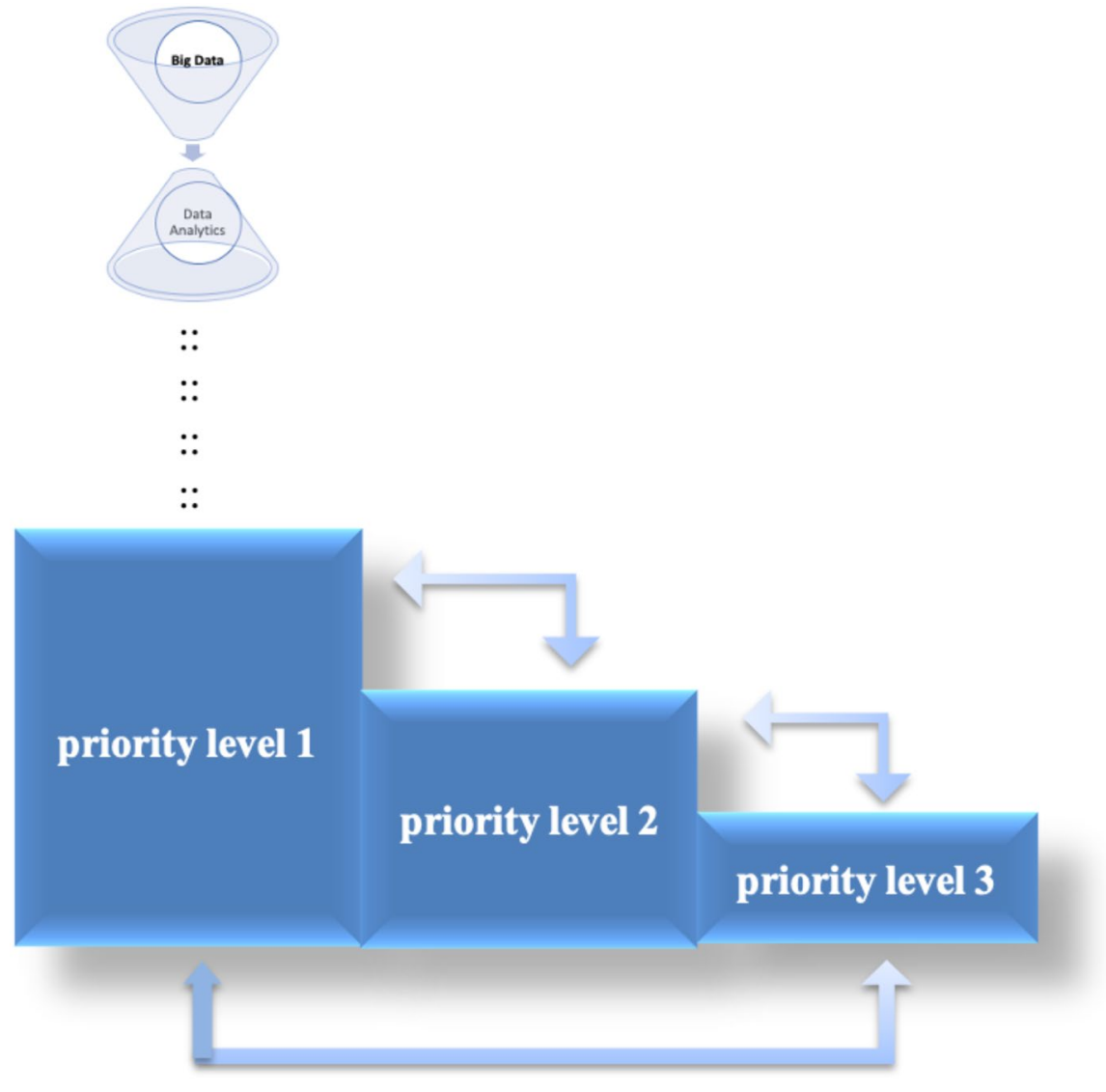

Fig. 2 A cascade of hierarchical urban data use

specifying successively: the policy-support conditions (Sect. 5.2); the urban value creation process (Sect. 5.3); the long-term XXQ performance analysis (based on what is called the 'flying disc' model) (Sect. 5.4); and, finally, a novel methodological design based on the 'blowing-up' principle in relation to the cascade and decomposition approach (Sect. 5.5).

\subsection{Smart decision-support indicators}

To highlight the scope of this study, a useful conceptual framework is provided for developing appropriate high-performing management and assessment systems. As indicated in Sect. 5.1, this architecture seeks to synthesise and present a multiplicity of interlinked cornerstones for competitive spatial performance policies of smart championing cities. This issue has also been dealt in the recent literature-in combination with various (real-time) evidence-based data sources-with a view to ensuring and improving future urban performance (Miller 2005; Stratigea 2012; Nijkamp and 
Kourtit 2013). The organisation of our new conceptual framework is inspired by what is called the 'flying disc model', originally introduced as a navigation tool for urban policy by Kourtit and Nijkamp (2013c). This tool will be further developed here for the purpose of providing a systemic tool for intelligent data-driven urban policy. This will be done by focusing on the functional spatial dimension and the functional division of smart cities by connecting, communicating, involving, and managing a wide variety of actors' functionalities and stakeholders' interests. A crucial tool here is the use of modern digital information systems, as well as intelligence policy tools and data analytics, to keep the modern city and its actors on track in an efficient way, while operating in an open and turbulent environment.

Our conceptual system consists of internal and external critical conditions and/or driving forces [critical success factors (CSFs)] represented by measurable key performance indicators (KPIs) as the 'drivers' for reliably assessing the competitive XXQ performance of smart cities. For both layers of conditions, a different but complementary methodological approach is employed. The external urban conditions are predominantly focussed on an analysis of macro- and meso- KPIs on a city scale, while the internal functional factors are generally based on a location-based geoscience analysis which provides for spatially detailed results. For example, this framework should enable us to assess the liveability conditions of districts, neighbourhoods or even streets in modern cities, so that a detailed picture of sound, safe and sustainable urban environments and achievements can be obtained. The related aim of this study is to highlight the question where (i.e. in which type of district or neighbourhood) the highest quality of urban space in a smart city can be found or created, and under which conditions. The analytical model of an outstanding performance framework may help us to understand how a certain type of policy analysis may have to be conducted with a view to evaluating the competitive XXQ performance of smart cities that is based on detailed assessments of mutually connected socio-economic and spatially or functionally connected sub-systems in a city (see also Sect. 5.4).

Our archetype model seeks to provide a strategic navigation mechanism — based on the above-mentioned cascade and decomposition principle and to suggest operational guidelines across multiple levels of (prioritised) urban quality conditions and factors in a comprehensive and systematic hierarchical micro-meso-macro framework (Kourtit and Nijkamp 2013c). Furthermore, this approach is also helpful for different types of interconnected key actors in the urban system to identify the critical options for an efficient adaptation and 'intelligent transformation' (instead of, for instance, an 'intelligent lockdown') and to define their responses to different types of short- and long-run disturbances, disruptions, crises or shocks, and stressors. Furthermore, it also mobilises multiple strategic resources that are able to generate the highest possible long-term synergetic added value that leads to sustainable and resilient societies or cities.

\subsection{Framework composition for urban value creation}

Our analysis framework consists of external critical success factors ("drivers") and internal factors (internal 'control variables') for assessing the competitive spatial performance of smart cities to enhance sustainability—or, in general, their 
$\mathrm{XXQ}$ - and to transform cities or communities in an intelligent way (in terms of new ways of living-e.g., health, safety, cohesion-and governance). The external drivers, a vital part of the multi-scale world-class capabilities framework, contain a complex set of key indicators at the macro, meso and micro level in terms of, for example, productivity, resource use, safety, health, sustainability advantages, etc. (Daniels and Moore 2002; OECD 2008). The internal dynamics in the complex city-economy is, in particular, based on an XXQ assessment at a disaggregated level of districts and neighbourhoods, including their resources or inputs that may contribute to enhance urban vitality and the overall sustainability at a region or city level (see, e.g., Santagata 2002; Gallopin 2006; Guzman 2017; Kourtit 2019). Smart cities have potential options or opportunities to respond and anticipate with a selected mix of intelligent resources, to the multiplicity of urban challenges_often called 'possibilism' (Vidal de la Blache 1903)—at different territorial levels. This 'possibilism' approach depends on their various socio-economic backgrounds and how much and which combination of resources they are able to use-i.e. 'the judge of their use'-(Johnston et al. 2000, p. 609)—-that determines their 'capability' to enhance their competitive performance and their wellbeing and sustainability (e.g., Sen 1980, 1999).

The internal and external forces and linked multiple resources may induce a pathway towards solving long-range (global) issues and exploiting society-relevant assets (both economic and non-economic). They may also add sustained value for shaping and managing modern world-class smart city systems for increasing the well-being and the sustainable competitiveness (through maximising the creation of the overall XXQ value (which consists of both tangible and increasingly of intangible assets) of the city's collective well-being (see Nijkamp 2008; Kourtit 2020).

The relevance of the notion of 'XXQ value creation' in the context of creating high value for multiple (from micro- to macro-) layers of actors and structures will be illustrated in this study by means of the presentation of an integrated systemic panorama of the intelligent 'power' of smart cities. Modern cities are complex and pluriform ecosystems that need both thorough scientific treatment and sustainable policy care. They need to be understood from their fundamental architecture, their composition, and their functioning, at all scales ranging from micro to meso/macro. Smart cities in a data-rich environment call for new and advanced systematic and operational data-rich intelligent decision-support tools, in particular, a systematic methodological interactive 'power of information' contribution for urban sustainability policy on the basis of extensive multivariate big data in a smart urban decision support system (see, e.g., Mayo and Steinberg 2007). This intelligent methodological systems approach is based in particular on:

- The use of systemic decomposition tools for the urban, suburban, semi-urban and rural space (the 'microcosmic city', in a decomposition perspective (see Mumford 1961; Hall 1998; Taylor 2004; Bettencourt et al. 2007)

- The use of (big) data metrics on small-scale hierarchically organised units in the city, as knowledge-based building blocks for understanding the real essence and dynamics of the modern city (the cascade structure). 
The microcosmic approach takes the cascade and decomposition argument further by arguing that the structured organisation of micro units in a city is a sine qua non for developing a comprehensive and interconnected view of the city. This microcosmic perspective is related not only to functional and smart specialisation in a city (including its morphology and land use), but also to the collection, storage and use of a multiplicity of relevant data. This multidimensional approach typifies the notion of 'unweaving' the poetry of a rainbow (Dawkins 1998) which allows us to strip the 'fata morgana' of the world-class smart city system of its wondrous veil of mystery and superior mirages. This is especially relevant in the context of novel research approaches to tackle global urgent or sensitive issues (e.g., poverty, climate change, viruses) through decomposing the main issue into smaller research questions and effective interventions in understanding a particular situation at all relevant scale levels. In this way one may arrive at a systematic and manageable mapping and improvement of the constituents of a long-term 'XXQ value creation' at various geographical scale and time levels.

This approach bears some similarity to the original research approach ('experimental science') of the 2019 Nobel laureates Banerjee, Duflo, and Kremer geared to 'alleviating global poverty' with reliable results and answers (based on truth values of the premises) from the research field (viz. deductions from theory; see also, e.g., Popper 1959). In this way, one may increase the high 'sources of value' of highly qualified information and thus advance the production and validation of socio-economic knowledge. This systematic decomposition approach may significantly transform and stimulate the methodology of various research programmes. This is clearly reflected in the emerging interest in what is called 'hierarchical decomposition' in the form of a multilevel cascade structure of aligned directions (i.e. the functional deconstruction) of the development of physical, and social and economic systems, as well as of cities' planning and policy constellations, into operational powerful sub-functions (even at the individual and disaggregate level, e.g. street-level information) (see, e.g., Simon 1955, 1962; Batty and Longley 1994; Frankhauser 1998; Chen 2011, 2012, 2016; Pumain and Moriconi-Ebrard 1997; Pumain 2006; Kourtit and Nijkamp 2018). This approach helps us to identify important patterns and effective strategic options and choices, and to understand the challenges, driving and sensible forces and other important stimuli on the 'body' and 'soul' of the city (see, e.g., Kourtit et al. 2020a; Wahlstrom et al. 2020a, b), and specific local needs that altogether are responsible for the economic and liveability achievements and support the 'XXQ value creation' of smart cities for the long-term.

In recent years, the importance and effects of scaling analysis, hierarchical modelling and the hierarchical organisation of complex (urban) systems (see, e.g., Zipf 1949; Christaller 1933; Beckmann 1958; Davis 1978; Woldenberg and Berry 1967) have prompted a widespread interest in systemic urban studies (see, e.g., West et al. 2002; Pumain and Moriconi-Ebrard 1997; Bettencourt et al. 2007; Batty 2006, 2008; Chen 2012; Bettencourt 2013; Frankhauser 1998; Pumain 2006; Rybski et al. 2009).

This new way of understanding and managing city dynamics, complex policy issues, functional flow networks, bilateral and multilevel connections and coordination efforts between (sub)functions and levels in the urban space-economy in combination with 'intelligent transformation' (ranging from big data to smart data 
management) is also represented in the recent 'collective intelligence' concept (see Dicken 1998; Dick 2005; Beaverstock et al. 1999, 2000; Nijkamp 2008; Nijkamp and Kourtit 2012; Kourtit 2019). Over the last 2 decades, it has prompted entirely new forms of urban communication and spatial interaction (e.g., in a citizen science context), with a significant and unprecedented impact on modern planning strategies and daily life in smart cities (Latour 1992; Verbeek 2006; Neal 2012; Waelbers 2009).

The benefit of the 'XXQ value creation' is that it helps modern cities discover the hidden or unknown opportunities and to anticipate 'grand' challenges at all relevant scale levels, so as to create and capture value for enhanced sustainability and intelligent governance, including a transformation through alternative ways of living, working and recreation, in order for them to become and stay successful world-class or high-performing smart cities. This will be further illustrated in the next sub-section by means of an experimental outline of sustainable smart city management for generating a high synergetic and sustained added value for urban world-class performance, with a view to encouraging a 'sustainable smart home' for citizens.

\subsection{Integrative 'XXQ value creation' model architecture}

The architecture of the long-term 'XXQ value creation' model, as described above, is based on a balanced combination of interconnected internal and external key drivers and is mapped out in greater detail in Fig. 3. This figure is inspired by earlier empirical smart urban modelling studies, in particular, Wahlstrom et al. (2020a, b) and Östh et al. (2020).

The 'umbrella' model depicted in Fig. 3 incorporates the cascade and the decomposition principle from Fig. 2, in terms of a systemic structure of hierarchically organised urban subsystems defined in terms of connectivity $(\mathrm{C})$, functionality $(\mathrm{F})$ and morphology (M) (internal factors) and moderated by various urban assets (or capital provisions). They all serve to enhance the city's performance, while being driven by human, institutional, and technological factors.

This model represents the balanced manoeuvre space for an ' $\mathrm{XXQ}$ value creation' mechanism-illustrating a balanced combination of prioritised endogenous and exogenous explanatory drivers and factors, also often called decision and condition variables (inputs and outputs, as well as linkages). Hence, the use of such a model may influence the multidimensional structures and levels of the overall value-added-based productivity and performance (XXQ) of smart cities. The model reflects the role of integrated contextual factors in a particular context, including the urban ambiance and regional profile. It links endogenous urban or regional development-in terms of innovation ecosystems and networks on knowledge and information as well as the local actions and synergy of all stakeholders-to better anticipate and exploit the smartness and intelligence of the city (e.g., Lundvall 1992; Malecki 2007; Huggins 2010; Storper 1997; Cooke et al. 1998, 2000; Winters 2011a).

This new development towards 'intelligent transformation' helps to present aligned strategic guidelines and actionable recommendations, with a strong stimulation of interfaces (systemic as is the nature of cause-and-effect chains), relationships 


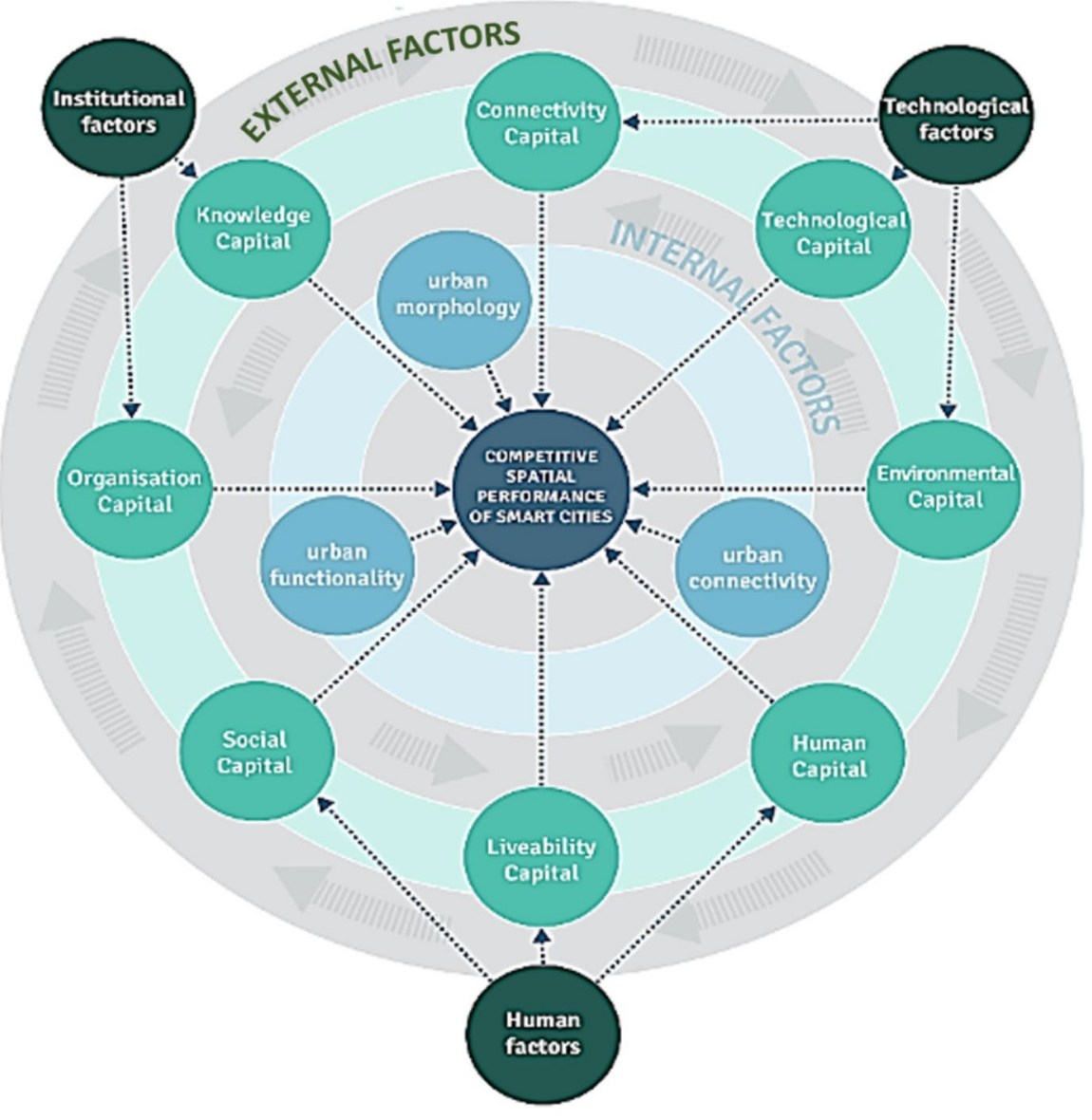

Fig. 3 Model of competitive spatial performance of smart cities. Source: Author's own elaboration from Kourtit and Nijkamp (2013c). Legend: The arrows refer to a connected decomposition of constituent factors, while the intensity of the green colour (from dark to light) refers to the level of impact detail of the external factors; the blue colour refers to the internal factors (colour figure online)

and hierarchies, for increasing the XXQ value and for developing sustained championing break-out strategies (e.g. due to differences between urban, semi-urban or rural areas and their constellations) in different institutional constellations, management processes, functional-economic segments, and public functions. This will result in a better and smartly restructured local governance, a participatory society, and data-accountability mechanisms (Rondinelli et al. 1989; Kulipossa 2004; Lange 2010; Rodden and Wibbels 2019). Such intelligent urban areas may form contiguous socio-economic spaces and corridors (Dicken 1998; Dick 2005; Bunnell and Maringanti 2010). The recent drastic advances in systematic and operational datarich intelligent decision-support tools may help to bring and integrate the various urban segments together, with the support of, for example, a blockchain blending 
technology and artificial intelligence. This will serve to build compatible information systems and create the most reliable smart solutions at smaller operational scales of the city to track value drivers and to generate and exchange socio-economic value for a long term. Furthermore, it may help to realise the implementation processes of intelligent and effective policy strategies and related actions, centred around key value drivers and factors, in an urban setting, as a result of real-time data and information provision, new forms of cooperation and dialogue, and the capability for regional growth and competitiveness (Inayatullah 2011; Winters 2011b; Lee et al. 2013; Gattulli et al. 2014.

The analytical microcosmic model (inspired by the 'flying disc model') helps to integrate micro-data on the internal characteristics of space (e.g., on a district and street scale) with meso-data on regional or city covariates in a multi-level cascade structure of interconnected strategic interactions with what is called here the 'blowing-up' method (see Sect. 5.5). This decomposition analysis is designed to coordinate complex interdependent task systems among a multiplicity of actors and stakeholders with limited cognitive capacity (smart governance through intelligent transformation) (see, e.g., Goldstein 1987, 2003; Sanchez and Mahoney 1996; Baldwin and Clark 2000a, b; Rivkin and Siggelkow 2003; Ethiraj and Levinthal 2004; Gelman and Hill 2007; Kourtit and Nijkamp 2018). Section 5.5 will then provide more details on this cascade and decomposition approach, by presenting the principles of the 'blowing-up' principle.

This cascading method serves several (sub-)functions and establishes an integrated information and communication infrastructure for collective decision-making (see, e.g., Chandler 1962; Galbraith 1973). Furthermore, it decomposes long-term common future-oriented values and expectations, shared strategic choices, longrange goals and visions, plausible prospects and pre-defined (value) conditions related to future images of a high-performing world-class smart city into a lowerdimensional structure (including strong interfaces with other subdivisions) with operational key sub-indicators based on different dimensions, combined with smart solutions to the benefit of urban (sub)systems for various stakeholders. In doing so, it respects several levels of accountability mechanisms that balance ongoing communication, big data and information-wealth processing, and joint and optimal smart decision-making, in particular in situations with multiple possible equilibria (Simon 1955, 1962; Chandler 1962; Galbraith 1973; Arrow 1974; Selten 1975; Becker and Murphy 1992), from forward-looking determinants (with interactive effects) and a long-term strategic policy perspective.

The value-based management in this ongoing process positions smart cities on the basis of their relative performance (a generalised productivity and efficiency measure), i.e. by relating their operational outputs (or resources) to their operational inputs-aiming for both input reductions and output increases-regarding their socio-economic achievements (see also Kourtit et al. 2013; Kourtit 2019). In this transformation process, using extended advanced methods helps not only to position smart cities, but also to identify the highest-performing, i.e. the highest-ranking, smart cities. Thus, the 'XXQ value creation' model encompasses critical key drivers and value conditions (as inputs) that can lead to effective strategic actions to maximise the productivity of smart cities. This can be measured along multiple relevant 
dimensions to provide transparent and intelligent solutions to reach the target metrics and optimal 'super-efficiency' level.

\subsection{The blowing-up decomposition methodology}

The blowing-up decomposition approach referred to above empowers urban systems with new insights and intelligence, allowing them to gain a better understanding of the dynamics through data transformation by providing a user-oriented information infrastructure and eliminating irrelevant measurements that have no clear explanatory meaning. This helps to avoid an 'unmanageable spaghetti tangle of systemic interconnections' (Langlois 2002, p. 5). The above-mentioned hierarchical decomposition principles are applied in many domains of social science research (Snijders and Bosker 1999; Kozlouski and Klein 2000; Lang and Bliese 2009; Corrado and Fingleton 2012; Nijkamp and Kourtit 2013c; Kourtit and Nijkamp 2018) and provide useful evaluation frameworks to study the integral behaviour of a system based on mutual connections.

The above-mentioned 'XXQ value creation' model identifies three distinct clusters of external drivers (see also Fig. 3). These were identified on the basis of the extensive systematic evaluation work of Nam and Pardo (2011) who conceptualised a smart city by means of three key dimensions: technology, People, and Institutions. Further identifying and clarifying which are the key conceptual components of a smart city, allowed these authors to decompose them into three categories of core factors for innovative action, as follows:

- Institutional factors (I) Connected with urban governance and policy, as well as with the external environment which supports innovations.

- Technological factors $(T)$ Refer mainly to the broadly defined infrastructure of the smart city, both physical as well as, its software (including data collection and handling).

- Human factors $(H)$ Concern pull factors, such as creativity, diversity, and education, but also formal and informal bonds, as well as social activity.

Further details can be found in Appendix A. The blowing-up approach provides a novel view of the essential role of these main drivers and helps to map out the highly interdependent and measurable components and tasks of the identified drivers in an 'XXQ value creation' model, while minimising the overlap and dependencies between the actionable strategies of each driver (see, e.g., Baldwin and Clark 2000a, b).

These multidimensional, often latent, drivers may be further decomposed and encapsulated into distinct categories of measurable indicators (the Key Performance Indicators-KPIs) that act as signposts for operationalising and implementing smart and intelligent urban solution strategies. And at the same time, this approach helps to connect the component chains for collecting and managing data from heterogeneous sources to develop a data warehouse - an architectural construct of a digital multi-level information management system (different from a container of 


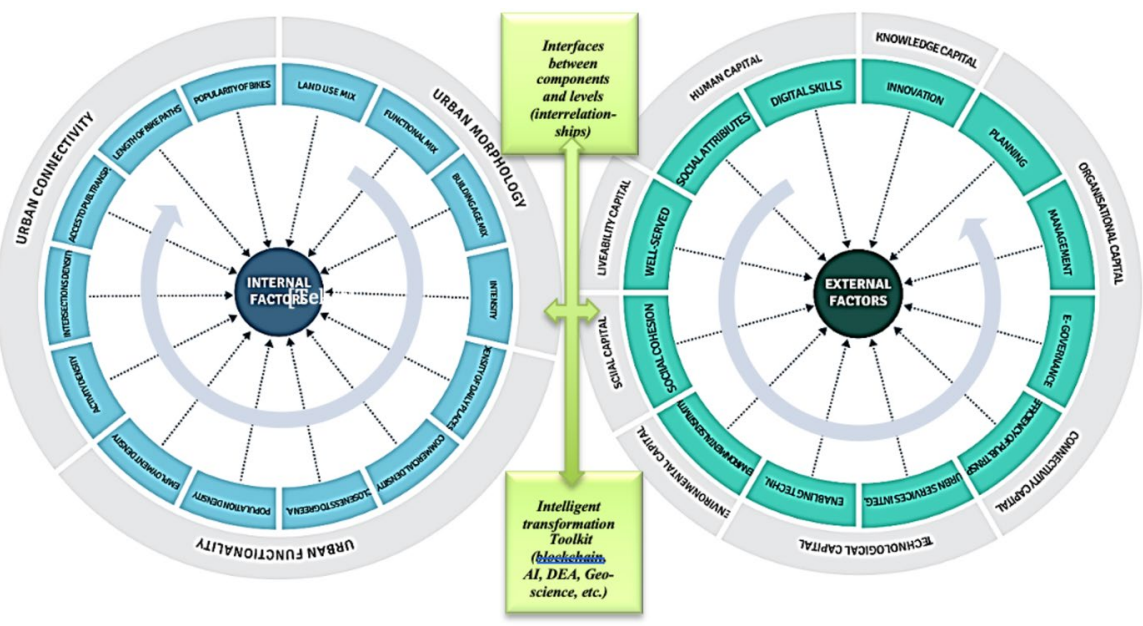

Fig. 4 Endogenous and exogenous explanatory drivers and factors of a smart urban. Fabric. Source: Author's own elaboration. A systemic constellation of the multidimensional determinants and critical factors shaping an intelligent city system

operational databases), as the core of 'intelligent transformation'. This will help to provide a meaningful strategic use of data and unlock valuable insights into concrete actions that should create values and accountabilities, and speed up the decisionmaking at various levels (see also Kourtit 2019), and which capture added-value outcomes leading to the high performance of a championing city.

The systematic architecture of the framework of the main critical drivers of an urban economy decomposed into the prioritised endogenous and exogenous explanatory drivers and factors is illustrated in Fig. 4. It is based on an overview of the existing literature-in combination with various (real-time) multiple sources of data, digital technology opportunities, balanced scorecards (BSCs) (e.g., Johnson and Kaplan 1987; Kapłan and Norton 1992) — and supported by built-in and customized algorithms (to cluster data, see, e.g., Po et al. 2009; Ross 2009; Rubio et al. 2015), DEA (data envelopment analysis) methods for relative closeness to the XXQ value (see, e.g., Charnes et al. 1978; Goudarzi and Ansari 2012), or interactive visualisation methods to assess the performance of urban space in smart cities.

The hierarchical construction which is basic to Fig. 4 presents the systematic typology of endogenous and exogenous explanatory drivers and factors for each of the identified three drivers concerned in an interactive learning environment and dialogue systems which help decision-makers and stakeholders to keep on track for facilitating (short and long term) strategic decisions and taking smart actions that should create value (see also, e.g., Galbraith 1977). More detailed, empirically based descriptions of these explanatory drivers and factors can be found in Appendix A.

This set of three common multidimensional components and their mutual strategic linkages allows us to regard the 'intelligent transformation' of the creation of the XXQ value for a smart city as an ongoing supporting intelligent process where the shaping and managing of modern world-class smart city systems takes place through 


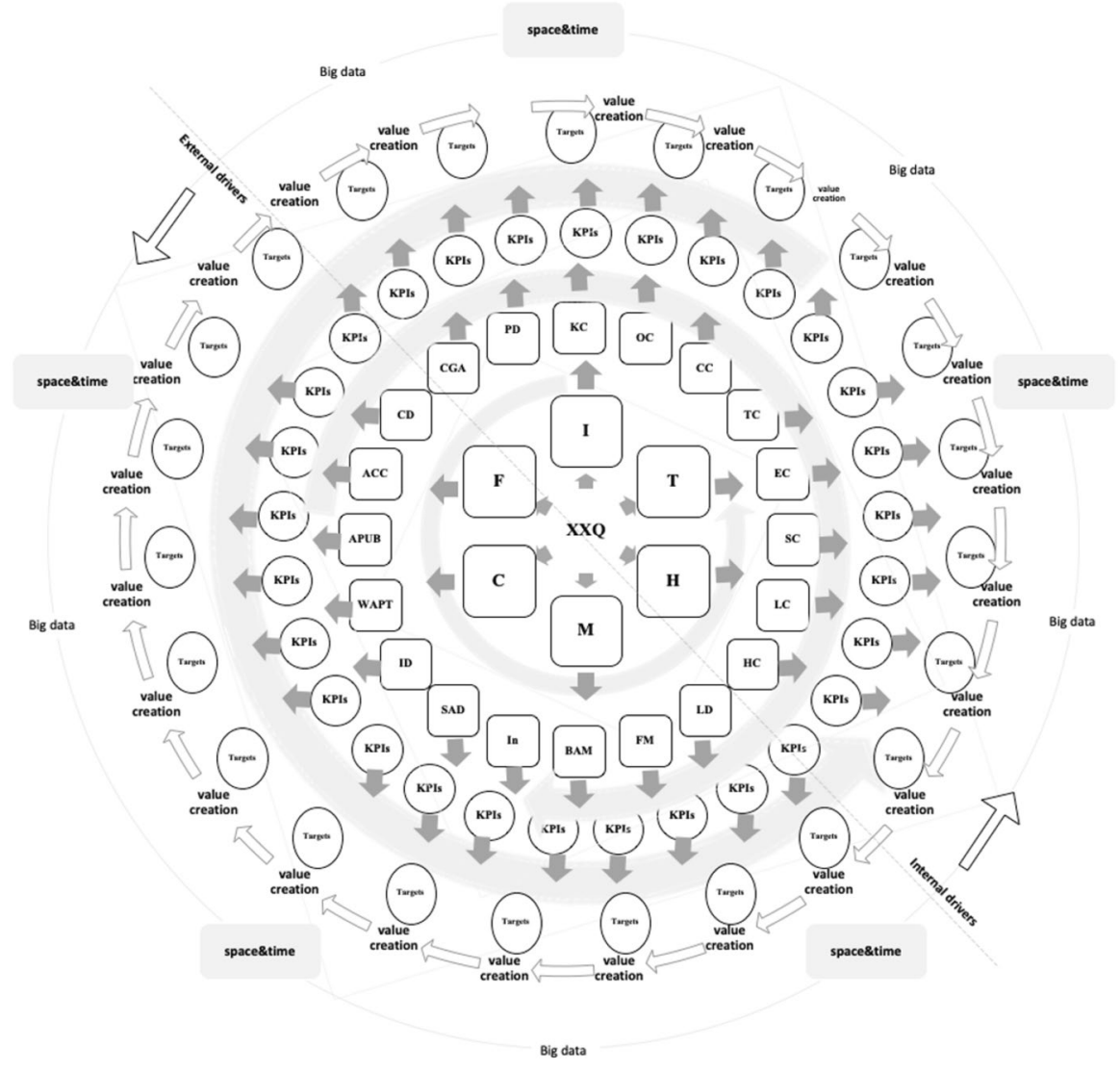

Fig. 5 The blowing-up XXQ value model. Source: Author's own elaboration. Figure maps out the complex force field of the systemic implications of the blowing-up principle for the XXQ value city system

a systematic, hierarchical and balanced decomposition of the XXQ-principle into clear critical socio-economic sub-conditions and alternative policy options. Furthermore, the operationalization of these elements also goes through an intelligent transformation of the sub-functions and real-time situational interfaces, as illustrated in Fig. 5 (see also Wahlstrom et al. 2020b; Kourtit and Nijkamp 2018).

This is further supported by advanced modelling tools and data mining techniqueswith the use of advanced communication systems and multiple-source and multidimensional data ('big data') systems. These 'big data' are produced by multiple actors and stakeholders at various geographical scales and time levels. These are systemically selected, following a cascade architecture, to capture the overall added-value outcomes that lead to the high performance of a championing city. 


\section{Conclusion}

Our study aimed to sketch out the principles, design and contours of city intelligence in the digital age. To become and remain a high-performing or even worldclass smart city, a sine qua non is a systematic and operational framework of reliable (internal and external) information systematisation, transparency, accessibility, monitoring and communication of urban achievements at relevant space-time levels, based on the involvement of important stakeholders. A smart city is a complex organism with different neighbourhoods, districts and streets. They are characterised by different urban fabrics and shaped by diverse processes, while facing a multiplicity of unforeseen options and possibilities, (digital) challenges, policy foundations, behavourial responses, far-reaching consequences and an avalanche of unstructured data. Therefore, there is an urgent need and requirement for effective and professional (evidence-based) well-informed smart (repositioning) strategies, actions and initiatives, intelligent future-oriented policies and governance initiatives, necessary spatial developments, and a systematic well-integrated data warehouse system.

In the current digital information society, the 'judge of their use' to bundle a selection of strategic options or opportunities (based on multiple information and data systems) that are meaningful for smart cities make it a necessity to proceed to 'no-nonsense' discussions and a value actions 'capabilities approach' to build a sustainable urban future and keep the city on track.

In the current dynamics of cities, this calls for clear guidance on how to identify, formulate, and characterise critical conditions and factors that range over different (sub)functions in a hierarchical system of all the elements that are necessary for world-class value creation, from the new viewpoint of consistent XXQorientation and big data management.

To create a better and strong understanding of the function of complexity and the interconnected concerns and opportunities of the quality-of-life conditions, it is necessary to perform a decomposition of the drivers' structure and a (re) construction of the aligned activities distributed across multiple levels of (prioritised) urban quality conditions and factors in a comprehensive and systematic hierarchical micro-meso-macro XXQ-framework. To ensure that this adequately satisfies the need to be able to anticipate, adapt, transform, change, and prosper in open and competitive urban systems requires an intelligent transformation in combination with modern big data management tools, and with the involvement of a multiplicity of actors and stakeholders in a multi-level urban system. This is an ongoing process in a new way of thinking and transformation, in search for alternative functional and structural designs - supported by digital and information methods and intelligent decision tools-in the XXQ-framework.

This approach opens new ways forward and will influence the current and future orientation and necessary change of (sub)functions, activities for creating flexibility in the strategic core domains of the urban system, and the general strategic core policy towards achieving the ideal level of quality of life. Ultimately, it will achieve an entirely different level of effectiveness, enhancements and improvement of the urban performance value at the interfaces of various spatial scales. 
Consequently, the creation of reliable, integrated and connected databases, supported by, for example, blockchain and/or artificial intelligent approaches (see e.g. Balan et al. 2020), and by up-to-date digital information systems, will certainly help to uncover they key drivers of urban dynamics. This may prompt functional changes which, in turn, will influence the overall value-added-based productivity becoming and remaining a high-performing smart city. In other words, this may help smart cities to integrate new and specific activities (anticipating) to empower their core competencies into their value chain activitiesusing a pluriform data set. This will enable these cities to keep on track and 'stay alive' without having to resort to an adaptation of any type of (intelligent) lockdown with a high-risk strategy for our well-being and the quality of our daily living and working environment in a broad sense, a state of mind sometimes also called 'city love' or 'neighbourhood love' (see e.g. Wahlstrom et al. 2020b). Clearly, smart city policy is not digital technology policy; it is based on a human-centered strategic view on the future of human settlements.

On the basis of the above exposition on intelligent city governance, we may formulate the following design and use principles for smart cities:

- Governance flexibility, ranging from long-term strategic envisioning experiments to daily online monitoring and managerial interventions.

- Cross-sectional applicability, ranging from systemic city planning to specific urban policy domains (e.g., human health, environmental quality, waste recycling, urban green, mobility, public space).

- User-participation potential, ranging from passive information provision and awareness creation possibilities to pro-active and citizen-oriented empowerment and participation (including democratic interactive opinion expression and structured image and scenario building-imagineering).

- Open access and digital transparency, with a view to user friendliness and suppression of complicated digital handling mechanisms for citizens.

- Development of operational performance indices which describe the actual and future states of a complex urban system from the perspective of sustainability and climate interests (e.g., urban circularity index, local or individual ecological footprint etc.).

In retrospect, this study is largely methodological and conceptual in nature. It was not meant to be an empirical study; its major aim was to present a systematic and novel architecture for intelligent city governance in the new digital age with an abundance of data. It should be noted, however, that several recent model studies (see the Reference list) by the authors have demonstrated the validity and practical usefulness of the framework proposed in our study. It goes without saying that our exploratory article, which brought together a wealth of interesting smart city studies, is only a first step. It needs clearly an operational follow-up in which the design and use framing of our study is tested in applied studies in different cities of the world. 


\section{Appendix A}

\section{Description of endogenous and exogenous explanatory drivers and factors}

- Institutional factors (I):

- Knowledge Capital (KC)—consists of share of knowledge workers in the total working population, rise in scientific and informatics activity, knowledge creation in terms of patent applications, higher education institutions, strength of higher education institutions, or R\&D expenditures in higher education.

- Organisation Capital (OC)_includes valuable and critical governance resources. In particular, transitional components comprise visions, leadership and organisational transformation in structure, governance and planning models (which stimulate an innovation system and promote new combinations of service delivery, as well as greater effectiveness, when researching the impact on the city), strategy-based approaches in planning, an integrated and transparent governance system, intersectoral partnerships and an innovative entrepreneurial climate, interoperable institutional readiness - collaborating across departments and with communities-to remove unnecessary legal and regulatory barriers.

- Technological factors (T):

- Connectivity Capital (CC)—includes mass transit facilities, airports, highways, ports, mobility systems for population and workforce, length of roads, motorways and rail tracks, number of telephone mainlines, as well as share of households with broadband connections.

- Technological Capital (TC)—contains specific technological components relating to the framework of smart city development, not only advanced physical infrastructure, enabling technologies, critical infrastructure components and services, but also Information and Communication Technology (ICT) resources, such as telecommunications access and use of digital government sources.

- Environmental Capital (EC) - the most prominent aspects are: sustainable resource and energy flows focussing on resource cycle management, a circular economy, environmental sensitivity and vulnerability, air and water pollution and climate resilience of urban structures.

- Human factors $(\mathrm{H})$ :

- Social Capital (SC)_including life-long learning, social and ethnic plurality, flexibility, creativity, cosmopolitanism or open-mindedness, and participation in public life. But also social learning, the social inclusion of various urban residents in public services, soft infrastructure (knowledge networks, voluntary organisations, crime-free environments), meeting points for professionals, an integrated approach to connecting among entire communities (governments, businesses, schools, non-profit organisations, and individual citizens), thereby advancing their collective skills and capacities; and multicultural neighbourhoods, as places of urban innovations, sustainable socio-economic growth, and the transformation of regions and cities. 
- Livability Capital (LC)—contains such factors as: quality of life, access to services and level of development of services of general interest, spatial equity, different types of smart user-oriented services; Internet-based government services that enable ubiquitous connectivity to transform key government processes, both internally across departments and employees and externally to citizens and businesses; access to urban amenities including all types of social infrastructure: health, sport, educational, and cultural including the level of development of e-services, and the affordability and quality of housing.

- Human Capital (HC) — consists of competences, social and personality attributes, such as level of digital literacy, share of economically active population, skilled labour force, per capita GDP, rise in knowledge intensity, share of higher wages, or level of educational attainment.

- Urban morphology consists of, for example, land use diversity (LUD), functional mix (FM), building age mix (BAM), Intensity (I), etc.

- Urban functionality comprises, for example, density of daily places (accessibility to basic services) (ACC), commercial density (CD), closeness to green areas (CGA), population density (PD), etc.

- Urban connectivity includes, for example, social activity density (SAD), intersections density (ID), walkable accessibility to public transportation nodes (WAPT), length and concentration of cycle paths (LCCP), accessibility and the popularity of urban bikes (APUB), etc.

Acknowledgements The author acknowledges the grant of the Axel och Margaret Ax:son Johnsons Stiftelse, Sweden. The author also acknowledges the grant of the Romanian Ministry of Research and Innovation, CNCS-UEFISCDI, project number PN-III-P4-ID-PCCF-2016-0166, within the PNCDI III" project ReGrowEU -Advancing ground-breaking research in regional growth and development theories, through a resilience approach: towards a convergent, balanced and sustainable European Union (Iasi, Romania).

Open Access This article is licensed under a Creative Commons Attribution 4.0 International License, which permits use, sharing, adaptation, distribution and reproduction in any medium or format, as long as you give appropriate credit to the original author(s) and the source, provide a link to the Creative Commons licence, and indicate if changes were made. The images or other third party material in this article are included in the article's Creative Commons licence, unless indicated otherwise in a credit line to the material. If material is not included in the article's Creative Commons licence and your intended use is not permitted by statutory regulation or exceeds the permitted use, you will need to obtain permission directly from the copyright holder. To view a copy of this licence, visit http://creativecommons.org/licen ses/by/4.0/.

\section{References}

Acs ZJ, Armington C (2006) Entrepreneurship, geography and American Economic Growth. Cambridge University Press, Cambridge

Albino V, Berardi U, Dangelico RM (2015) Smart cities: definitions, dimensions, performance, and initiatives. J Urban Technol 22(1):3-21

Alexander C (1964) Notes on the synthesis of form. Harvard University Press, Cambridge

Alexander C, Ishikawa S, Silverstien M (1977) A pattern language: towns, buildings, construction. Oxford University Press, New York 
Allison E, Peters L (2011) Historic preservation and the livable city. Wiley, Hoboken

Angelidou M (2014) Smart cities: a conjuncture of four forces. Cities 47:95-106

Arrow KJ (1974) The limits of organization. W.W. Norton \& Company, New York

Balan, A., Alboaie, S., Kourtit, K., and Nijkamp, P. (2020), Blockchain Systems for Smart Cities and

Regions - An Illustration of Self-Sovereign Data Governance, Knowledge Management for Regional Policy-Making (R. Laurini, P. Nijkamp, K. Kourtit, and L. Bouzouina (eds.)), SpringerVerlag, Berlin. (forthcoming)

Baldwin CY, Clark KB (2000a) Design rules: the power of modularity, 1st edn. MIT Press, Cambridge

Baldwin CY, Clark KB (2000b) Design rules the power of modularity. MIT Press, Cambridge

Bartolini N (2013) Rome's pasts and the creation of new urban spaces: brecciation, matter, and the play of surfaces and depths. Environ Plan D Soc Space 31(6):1041-1061

Batty M (2006) Hierarchy in cities and city systems. In: Pumain D (ed) Hierarchy in natural and social sciences. Springer, Dordrecht, pp 143-168

Batty M (2008) The size, scale, and shape of cities. Science 319:769-771

Batty M (2013) The new science of cities. MIT Press, Cambridge

Batty M, Longley PA (1994) Fractal cities: a geometry of form and function. Academic Press, London

Baycan T, Batey P, Nijkamp P, Button K (eds) (2008) Urban planning (classics in planning), vol 9. Edward Elgar, Cheltenham

Beaverstock JV, Smith RG, Taylor PJ (1999) A roster of world cities. Cities 16:445-458

Beaverstock JV, Smith RG, Taylor PJ (2000) World-city network: a new metageography. Ann Assoc Am Geogr 90(1):123-134

Becker GS, Murphy KM (1992) The division of labor, coordination costs, and knowledge. Q J Econ 107(4):1137-1160

Beckmann MJ (1958) City hierarchies and distribution of city sizes. Econ Dev Cult Change 6(3):243-248

Berry CR, Glaeser EL (2005) The divergence of human capital levels across cities. Pap Reg Sci 84:407-444

Bettencourt LM (2013) The origins of scaling in cities. Science 340:1438-1441

Bettencourt LM, Lobo J, Helbing D, Kühnert C, West GB (2007) Growth, innovation, scaling, and the pace of life in cities. Proc Natl Acad Sci USA 104:7301-7306

Bianca S (2001) Resources for sustaining cultural identity. In: Serageldin I, Schluger E, Martin-Brown J (eds) Historic cities and secret sites cultural roots for urban futures. World Bank, Washington, pp $18-22$

Brakman S, Garretsen H, van Marrewijk C (2011) The new introduction to geographical economics. Cambridge University Press, Cambridge

Brenner N (2013) Thesis on urbanization. Public Culture 25(1):85-114

Bunnell T, Maringanti A (2010) Practising urban and regional research beyond metrocentricity. Int J Urban Reg Res 34(2):415-420

Capello R, Nijkamp P (2009) Introduction: regional growth and development theories in the twenty-first century-recent theoretical advances and future challenges. In: Capello R, Nijkamp P (eds) Handbook of regional growth and development theories. Edward Elgar Publishing, Cheltenham, pp 1-16

Caragliu A, Del Bo C, Nijkamp P (2011) Smart cities in Europe. J Urban Technol 18(2):65-82

Castells M (1996) The rise of the network society, the information age: economy society and culture. Blackwell, Cambridge

Ceccaroni L, Piera J (2017) Analyzing the role of citizen science in modern research. IGI Global, Hershey

Chandler ADJ (1962) Strategy and structure: chapters in the history of the American Industrial Enterprise. MIT Press, Cambridge

Charnes A, Cooper W, Rhodes E (1978) Measuring the efficiency of decision making units. Eur J Oper Res 2:429-444

Chen YG (2011) Fractal systems of central places based on intermittency of space-filling. Chaos Solitons Fractals 44(8):619-632

Chen YG (2012) The rank-size scaling law and entropy-maximizing principle. Phys A 391(3):767-778

Chen YG (2016) The evolution of Zipf's law indicative of city development. Phys A 443:555-567

Chourabi H, Nam T, Walker S, Gil-Garcia RJ, Mellouli S, Nahon K (2012) Understanding smart cities: an integrative framework. In: Sprague RH (eds) Proceedings of the 45th Hawaii international conference on system sciences, Maui, Hawaii, 04-07 January 2012, IEEE, Piscataway, New Jersey, pp 2289-2297

Christaller W (1933) Central places in Southern Germany. Prentice Hall, Englewood Cliffs 
Cocchia A (2014) Smart and digital city: a systematic literature review. In: Dameri R, Rosenthal-Sabroux $\mathrm{C}$ (eds) Smart city, progress in IS. Springer, Cham

Coe A, Paquet G, Roy J (2001) E-Governance and smart communities: a social learning challenge. Soc Sci Comput Rev 19(1):80-93

Cohen B (2014) The 10 smartest cities in Europe, Fast Company. http://www.fastcoexist.com. Accessed 25 June 2014

Cooke P, Uranga MG, Etxebarria G (1998) Regional systems of innovation: an evolutionary perspective. Environ Plan A 30:1563-1584

Cooke P, Boekholt P, Tödtling F (2000) The Governance of Innovation in Europe. Pinter, London

Corner J (1999) Recovering landscapes. Princeton Architectural Press, New York

Corrado L, Fingleton B (2012) Where is the economics in spatial econometrics? J Reg Sci 52:210-239

Courage C, McKeown A (2019) Creative placemaking: research, theory and practice. Routledge, Routledge

Crescenzi R, Rodríguez-Pose A (2008) Infrastructure endowment and investment as determinants of regional growth in the European Union. EIB Pap 13:62-101

Cullen G (1961) The concise townscape. Reinhold, New York

Daniels PL, Moore S (2002) Approaches for quantifying the metabolism of physical economies, part I: methodological overview. J Ind Ecol 5(4):69-93

Davis K (1978) World urbanization: 1950-1970. In: Bourne IS, Simons JW (eds) Systems of cities. Oxford University Press, New York, pp 92-100

Dawkins R (1998) Unweaving the rainbow. Houghton Mifflin, Boston

Dick H (2005) Southeast Asia as an open system: geo-politics and economic geography. In: Kratoska PH, Raben R, Schulte Nordholt H (eds) Locating Southeast Asia: geographies of knowledge and politics of space. Singapore University Press, Singapore, pp 250-274

Dicken P (1998) Global shift: reshaping the global economic map in the 21st century, 3rd edn. Sage, London

Erkan Y, Ceccarelli P (2017) Communicating heritage: new symbolic values for historic walls. http:// www.unesco.org/new/fileadmin/MULTIMEDIA/FIELD/Venice/pdf/news/HW2017_Panel3.pdf. Accessed 27 Jan 2017. https://en.unesco.org/events/walled-cities-open-societies-managing-histo ric-walls-urban-world-heritage-properties

Ethiraj SK, Levinthal D (2004) Modularity and innovation in complex systems. Manag Sci 50(2):159-173

Ewing R, Clemente O (2013) Measuring urban design: metrics for livable places. Island Press, Washington

Foth M (ed) (2008) Handbook of research on urban informatics: the practice and promise of the real-time city. IGI Global, Hershey

Frankhauser P (1998) The fractal approach: a new tool for the spatial analysis of urban agglomerations. Popul Engl Sel 10(1):205-240

Friedmann J (2010) Place and place-making in cities: a global perspective. Plan Theory Pract 11(2):149-165

Fujita M, Thisse JF (2002) Economics of agglomeration: cities, industrial location, and regional growth. Cambridge University Press, Cambridge

Fujita M, Thisse JF (2012) Economics of agglomeration: cities, industrial location and regional growth, 2nd edn. Cambridge University Press, Cambridge

Galbraith JR (1973) Designing complex organizations. Addison Wesley, Reading

Galbraith JR (1977) Organization design. Addison Wesley, Reading

Gallopin GC (2006) Linkages between vulnerability, resilience and adaptive capacity. Global Environ Change 16:293-303

Gattulli V, Potenza F, Graziosi F, Federici F, Colarieti A, Faccio M (2014) Distributed structural monitoring for a smart city in a seismic area. Key Eng Mater 628:123-135. https://doi.org/10.4028/www. scientific.net/kem.628.123

Gehl J (1987) Life between buildings: using public space, translated by Jo Koch. Van Nostrand Reinhold, New York

Gehl J, Gemzøe L (2001) New city spaces, 2nd edn. The Danish Architectural Press, Copenhagen

Gelman A, Hill J (2007) Data analysis using regression and multilevel/hierarchical models. Cambridge University Press, Cambridge

Giffinger R, Haindl G (2009) Smart cities rankings: an effective instrument for the positioning of the cities?, Barcelona, Año IV, núm. 12 Febrero. p 7-25. http://upcommons.upc.edu/bitstream/handl 
e/2099/11933/05_PROCEEDINGS_M5_01_0014.pdf?sequence=1. Accessed Año IV, núm. 12 Febrero

Glaeser E, Kourtit K, Nijkamp P (eds) (2020) Urban empires. Routledge, New York

Goldstein H (1987) Multilevel models in educational and social research. Oxford University Press, New York

Goldstein H (2003) Multilevel modelling of educational data. In: Courgeau D (ed) Methodology and epistomology of multilevel analysis, chapter 1. Kluwer, London, pp 25-42

Gottdiener M (1985) The social production of urban space, 2nd edn. University of Texas Press, Austin

Goudarzi M, Ansari J (2012) Clustering decision making units (DMUs) using full dimensional efficient facets (FDEFs) of PPS with BCC technology. Appl Math Sci 6(29):1431-1452

Guzman PC (2017) World heritage cities and sustainable urban development: bridging global and local levels in monitoring the sustainable urban development of world heritage cities. Technische Universiteit Eindhoven, Eindhoven

Hall PG (1998) Cities in civilization. Pantheon Books, New York

Harvey D (2014) Cites or urbanization? In: Brenner N (ed) Implosions/explosions: towards a study of planetary urbanization. Jovis, Berlin, pp 52-66

Ho KS, Mckay RB (2002) Innovative performance measurement; balance scorecard-tow perspectives. CPA J 72(3):20-25

Hollands R (2008) Will the real smart city stand up? City 12(3):302-320

Huggins R (2010) Forms of network resource: knowledge access and the role of inter-firm networks. Int J Manag Rev 12(3):335-352

Inayatullah S (2011) City futures in transformation: emerging issues and case studies. Futures 43(7):654-661

Jacobs J (1961) The death and life of Great American cities. Random House, New York

Jacobs J (1969) The economy of cities. Vintage, New York

Jacobs J (1998) The edge of empire: postcolonialism and the city. Routledge, London

Johnson HT, Kaplan RS (1987) Relevance lost. Harvard Business School Press, Boston

Johnston RJ, Gregory D, Pratt G, Watts M (2000) The dictionary of human geography. Blackwell, Oxford

Kapłan R, Norton D (1992) The balanced scorecard-measures that drive performance. Harv Bus Rev 1(70):172

Karlsson C, Johansson B, Stough R (eds) (2011) Innovation agglomeration and regional competition. Edward Elgar, Cheltenham

Kasprisin R (2011) Urban design: the composition of complexity. Routledge, London

Kitchin R (2015) The opportunities, challenges and risks of big data for official statistics. J Int Assoc Off Stat 31:471-481

Kitchin R, Perng SY (2016) Code and the city. Routledge, London

Komninos N (2011) Intelligent Cities: Variable Geometries of Spatial Intelligence. Intelligent Building International 3(3):172-188

Komninos N, Kakderi C (2019) Smart cities in the post-algorithmic era integrating. Edward Elgar, Cities series

Kourtit K (2019) The new urban world: economic-geographical studies on the performance of urban systems. Shaker, Aachen

Kourtit K (2020) The digital urban challenge: intelligent response and smart governance of cities. Shaker, Aachen

Kourtit K, Nijkamp P (2013a) The use of visual decision support tools in an interactive stakeholder analysis—old ports as new magnets for creative urban development. Sustainability 5:4379-4405

Kourtit K, Nijkamp P (2013b) Introduction: regional innovation hotspots and spatial development. J Reg Sci 53:745-748

Kourtit K, Nijkamp P (2013c) In search of creative champions in high-tech spaces: a spatial application of strategic performance management. J Reg Sci 53:749-777

Kourtit K, Nijkamp P (2018) Big data dashboards as smart decision support tools for i-cities-an experiment on Stockholm. Land Use Policy 71:24-35

Kourtit K, Nijkamp P, Stough R (eds) (2011) Drivers of innovation, entrepreneurship and regional dynamics. Springer, Berlin

Kourtit K, Nijkamp P, Suzuki S (2013) Exceptional places: the rat race between world cities. Comput Environ Urban Syst 38:67-77

Kourtit K, Nijkamp P, Franklin RS, Rodríguez-Pose A (2014) A blueprint for strategic urban research: the 'Urban Piazza.' Town Plan Rev 85(1):97-126 
Kourtit K, Nijkamp P, Stough R (eds) (2015a) The rise of the city: spatial dynamics in the urban century. Edward Elgar, Cheltenham

Kourtit K, Nijkamp P, Steenbruggen J (2015b) The significance of digital data systems for smart city policy. Soc Econ Plan Sci 8(3):231-247

Kourtit K, Nijkamp P, Stough R (eds) (2017) Modelling regional growth and innovation. Int Reg Sci Rev 41(1):3-6. https://doi.org/10.1177/0160017617698743

Kourtit K, Nijkamp P, Stough RR (2019) Quality and inequality in urban and regional systems. Region 5(4):E1-E5. https://doi.org/10.18335/region.v5i4.257

Kourtit K, Nijkamp P, Elmlund P (2020a) The urban data deluge: challenges for smart urban planning in the third data revolution. Int J Urban Sci. https://doi.org/10.1080/12265934.2020.1755353

Kourtit K, Nijkamp P, Suzuki S (2020b) Are global cities sustainability champions? A double delinking analysis of environmental performance of urban agglomerations. Sci Total Environ 709. https://doi. org/10.1016/j.scitotenv.2019.134963

Kozlowski SWJ, Klein KJ (2000) A multilevel approach to theory and research in organizations: contextual, temporal, and emergent processes. In: Klein KJ, Kozlowski SWJ (eds) Multilevel theory, research, and methods in organizations: foundations, extensions, and new directions. Jossey-Bass, San Francisco, pp 3-90

Kropf K (2017) The handbook of urban morphology, the urban handbook series. Wiley, Chichester

Kulipossa FP (2004) Decentralisation and democracy in developing countries: an overview. Dev Pract 14(6):768-779

Lang JWB, Bliese PD (2009) General mental ability and two types of adaptation to unforeseen change: applying discontinuous growth models to the task-change paradigm. J Appl Psychol 94(2):411-428

Lange FE (2010) Urban governance, an essential determinant of city development? World Vision Institute for Research and Development, Friedrichsdorf

Langlois RN (2002) Modularity in technology and organization. J Econ Behav Org 49(1):19-37

Latour B (1992) Where are the missing masses? The sociology of a few mundane artifacts. In: Bijker W, Law J (eds) In shaping technology-building society, studies in sociotechnical change. MIT Press, Cambridge, pp 225-258

Lee JH, Phaal R, Lee SH (2013) An integrated service-device-technology roadmap for smart city development. Technol Forecast Soc Change 80(2):286-306

Lefebrve H (1991) The production of space. Blackwell Publishers, Oxford

Lefebvre H (1947) Critique de la Vie Quotidienne. L'Arche, Paris

Lefebvre H (1969) The explosion, marxism and the French revolution, trans. A Ehrenfeld. Monthly Review Press, New York

Lefebvre H (1996) [1967] The right to the city. In: Kofman E, Lebas E (eds) Writing on cities. Blackwell, London, pp 63-184

Lefebvre H (2003) [1970], The urban revolution. In: Bononno R (eds) University of Minnesota Press, Minneapolis.

Lombardi P, Giordano S, Caragliu A, Del Bo C, Deakin M, Nijkamp P, Kourtit K, Farouh H (2012) An advanced triple-helix network model for smart cities performance. In: Erkoskun OY (ed) Green and ecological technologies for urban planning: creating smart cities. IGI Global, Hershey, pp $59-73$

Lundvall BÅ (1992) National innovation systems: towards a theory of innovation and interactive learning. Pinter Publishers, London

Lynch K (1960) The image of the city. The MIT Press, Cambridge

Malecki EJ (2007) Cities and regions competing in the global economy: knowledge and local development policies. Environ Plan C Gov Policy 25:638-654

Martens E, Weijers Y (2000) Integratiemonitor 2000 Institute For Sociological-Economic Research (ISEO). Rotterdam 100:103-104

Mayo E, Steinberg T (2007) The power of information: an independent review, Cabinet Office, London. https://ntouk.files.wordpress.com/2015/06/power_information.pdf. Accessed June 2007

McKinley DC, Miller-Rushing AJ, Ballard HL et al (2017) Citizen science can improve conservation science, natural resource management, and environmental protection. Biol Conserv 208:15-28

Miller CA (2005) New civic epistemologies of quantification: making sense of indicators of local and global sustainability. Sci Technol Hum Values 30(3):403-432

Mosler S (2019) Everyday heritage concept as an approach to place-making process in the urban landscape. J Urban Des 24(5):778-793 
Mumford L (1961) The city in history: its origins, its transformation, and its prospects, harcourt. Brace \& World, San Diego

Nadi R, Soite W, Tafahomi R (2016) Dehistoricisation the urban landscape through transition of the enclosure ratio in urban fabric of Gonabad City in Iran. J Archit Eng Technol 5:162. https://doi. org/10.4172/2168-9717.1000162

Nam T, Pardo TA (2011) Conceptualizing smart city with dimensions of technology, people, and institutions. In: Proceedings of the 12th annual international digital government research conference on digital government innovation in challenging times, College Park, MD, USA, 12-15 June 2011, pp 282-291.

Neal Z (2012) The connected city. Routledge, New York

Neirotti P, Marco A, Cagliano AC, Mangano G, Scorrano F (2014) Current trends in smart city initiatives: some stylised facts. Cities 38(1):25-36

Nijkamp P (2008) XXQ factors for sustainable urban development. Rom J Reg Sci 2(1):1-34

Nijkamp P, Kourtit K (2013) The 'New Urban Europe': global challenges and local responses in the urban century. Eur Plan Stud 21(3):291-315

Nijkamp P, Kourtit K, Kocornik-Mina A (eds) (2020) Sustainable villages and green landscapes in the 'New Urban World.' Shaker, Aachen

OECD (2008) Handbook on constructing composite indicators: methodology and user guide. OECD (Organisation for Economic Co-operation and Development), Paris, p 158

Östh J, Kourtit K, Nijkamp P (2020) My home is my castle-assessment of city love in Sweden. Int J Inf Manag. https://doi.org/10.1016/j.ijinfomgt.2020.102213

Park RE, Burgess EW, McKenzie RD (1925) The city. University of Chicago Press, Chicago

Po RW, Guh YY, Yang MS (2009) A new clustering approach using data envelopment analysis. Eur J Oper Res 199(1):276-284

Popper KR (1959) The logic of scientific discovery. Hutchison, London

Pumain D (2006) Alternative explanations of hierarchical differentiation in urban systems. Hierarchy in natural and social sciences, Methodos series, 3rd edn. Springer, Dordrecht, pp 169-222

Pumain D, Moriconi-Ebrard F (1997) City size distributions and metropolisation. GeoJournal 43(4):307-314

Ratti C, Sobolevsky S, Calabrese F, Andris C, Reades J, Martino M, Claxton R, Strogatz SH (2010) Redrawing the map of Great Britain from a network of human interactions. Plos One 5(12). https:// doi.org/10.1371/journal.pone.0014248

Ratti V, Hassiotis A, Crabtree J, Deb S, Gallagher P, Unwin G (2016) The effectiveness of person-centred planning for people with intellectual disabilities: a systematic review. Res Dev Disabil 57:63-84

Redding SJ (2010) The empirics of new economic geography. J Reg Sci 50(1):297-311

Riesch H, Potter C (2014) Citizen science as seen by scientists: methodological, epistemological and ethical dimensions. Public Underst Sci 23(1):107-120

Rivkin JW, Siggelkow N (2003) Balancing search and stability: interdependencies among elements of organizational design. Manag Sci 49(3):290-311

Rodden JA, Wibbels E (2019) Decentralized governance and accountability. Cambridge University Press, Cambridge

Rondinelli DA, McCullough JS, Johnson RW (1989) Analysing decentralization policies in developing countries: a political-economy framework. Dev Change 20(1):57-87

Ross TJ (2009) Fuzzy logic with engineering applications. Wiley, Chichester

Rubio E, Castillo O, Melin P (2015) A new interval type-2 fuzzy possibilistic C-means clustering algorithm. In: Paper presented at the fuzzy information processing society (NAFIPS) held jointly with 2015 5th World conference on soft computing (WConSC), annual conference of the North American, Redmond, WA, USA.

Rybski D, Buldyrev SV, Havlin S, Liljeros F, Hernán A, Makse HA (2009) Scaling laws of human interaction activity. PNAS 106(31):12640-12645

Sanchez R, Mahoney JT (1996) Modularity, flexibility and knowledge management in product and organization design. Strateg Manag J 17:63-76

Santagata W (2002) Cultural districts, property rights and sustainable economic growth. Int J Urban Reg Res 26:9-23

Saunders P (1981) Social theory and the urban question. Hutchinson, London

Selten R (1975) Reexamination of the perfectness concept for equilibrium points in extensive games. Int J Game Theory 4:25-55 
Sen A (1980) Equality of what? In: McMurrin J (ed) The tanner lectures on human values. Cambridge University, Cambridge, pp 197-220

Sen A (1999) Development as freedom. Knopf, New York

Shapiro JM (2008) Smart cities: quality of life, productivity, and the growth effects of human capital. Rev Econ Stat 88(2):324-335

Silberberg S, Lorah K, Disbrow R, Muessig A (2013) Places in the making: how placemaking builds places and communities. Massachusetts Institute of Technology, Cambridge

Simon HA (1955) A behavioral model of rational choice. Q J Econ 69(1):99-118

Simon HA (1962) The architecture of complexity. Proc Am Philos Soc 106(6):467-482

Snijders T, Bosker R (1999) Multilevel analysis: an introduction to basic and advanced multilevel modeling. SAGE Publications, London

Stimson R, Stough RR, Nijkamp P (eds) (2011) Endogenous regional development: perspectives, measurement and empirical investigation. Edward Elgar, Cheltenham

Storper M (1997) The regional world. Guilford Press, New York

Stough RR, Kourtit K, Nijkamp P (2018) Quality and inequality in regional and urban systems. Region 5(4)

Stratigea A (2012) The concept of 'Smart Cities'. Towards community development? Terrains du Numérique Etudes de Cas 26(3/4):375-388

Taylor PJ (2004) World city network a global urban analysis. Routledge, London

Tuck E, McKenzie M (2015) Place in research: theory, methodology, and methods. Routledge, New York

Tuck E, McKenzie M, McCoy K (2014) Land education: indigenous post-colonial, and decolonizing perspectives on place and environmental education research. Environ Educ Res 20(1):1-23

Tureckova K, Nevima J (2020) The cost benefit analysis for the concept of a smart city. Sustainability 12:2663. https://doi.org/10.3390/su12072663

Verbeek PP (2006) Materializing morality. Sci Technol Hum Values 31(3):361-380

Vidal de la Blache P (1903) Tableau de la Géographic de la France. Hachette, Paris

Waelbers K (2009) Technological delegation: responsibility for the unintended. Sci Eng Ethics 15(1):51-68

Wahlstrom M, Kourtit K, Nijkamp P (2020) How to make cities the home of people-a 'Soul and Body' analysis of urban attractiveness. Land Use Policy. https://doi.org/10.1016/j.landusepol.2020.10473 4

Wahlstrom M, Kourtit K, Nijkamp P (2020) Planning Cities4People-a body and soul analysis of urban neighbourhoods. Public Manag Rev. https://doi.org/10.1080/1479037.2020.1718190

West GB, Woodruff WH, Brown JH (2002) Allometric scaling of metabolic rate from molecules and mitochondria to cells and mammals. PNAS 99:2473-2478

Whyte WH (1960) The organization man. Harmondsworth, Penguin (First published 1956)

Whyte WH (1989) Social life of small urban space. Municipal Art Society of New York (Film), New York

Winters JV (2011) Human capital, higher education institutions, and quality of life. Reg Sci Urban Econ 41(5):446-454

Winters JV (2011) Why are smart cities growing? Who moves and who stays. J Reg Sci 51:253-270

Wirth L (1938) Urbanism as a way of life. Am J Sociol 44(1):1-24

Woldenberg MJ, Berry BJL (1967) Rivers and central places: analogous systems? J Reg Sci 7(2):129-139

Zheng Y, Capra L, Wolfson O, Yang H (2014) Urban Computing: concepts, methodologies, and applications. ACM Trans Intell Syst Technol 5(3):55. https://doi.org/10.1145/2629592

Zipf GK (1949) Human behavior and the principle of least effort. Addison-Wesley, Reading

Zorbaugh HW (1929) The gold coast and the slum: a Sociological Study of Chicago's Near North Side. Chicago University Press, Chicago

Publisher's Note Springer Nature remains neutral with regard to jurisdictional claims in published maps and institutional affiliations. 


\section{Authors and Affiliations}

\section{Karima Kourtit ${ }^{1,2,3,4,5}$ (D)}

1 Open University of the Netherlands, Heerlen, The Netherlands

2 Alexandru Ioan Cuza University, Iasi, Romania

3 Polytecnic University Polytecnic University (UM6P), Benguerir, Morocco

4 Uppsala University, Uppsala, Sweden

5 Centre for the Future of Places (CFP), KTH Royal Institute of Technology, Stockholm, Sweden 